\title{
Identifikasi Kesulitan Mahasiswa Dalam Memecahkan Masalah Open Ended Materi Nilai Mutlak
}

\section{The Identification Of Students' Learning Difficulties Related To The Open Ended Problem In Absolute}

\author{
Mohammad Faizal Amir \\ PGSD FKIP Universitas Muhammadiyah Sidoarjo \\ * Korespondensi Penulis. E-mail: faizal.amir@umsida.ac, Telp: +6285706670541
}

Tujuan penelitian ini adalah untuk mengidentifikasi jenis dan faktor penyebab kesulitan mahasiswa dalam memecahkan masalah matematika berbasis open ended materi nilai mutlak berbentuk persamaan dan pertidaksamaan, serta memberikan saran untuk dosen. Subjek penelitian terdiri dari 138 mahasiswa PGSD UMSIDA pada matakuliah konsep dasar matematika tahun ajaran 2016-2017. Metode penelitian yang digunakan adalah kualitatif deskriptif. Instrumen penelitian terdiri dari Lembar Tes Pengetahun Nilai Mutlak dan pedoman wawancara. Berdasarkan data, jenis- jenis kesulitan mahasiswa meliputi tidak dapat sepenuhnya mengaplikasikan konsep jarak dan definisi nilai mutlak sehingga langkah penyelesaian tidak tuntas; mengalami misunderstanding syarat nilai mutlak; mengalami miskonsepsi berupa anggapan nilai mutlak selalu bernilai positif; mengalami kesulitan dalam hal konseptual, prosedural, dan algoritma. Faktorfaktor penyebab kesulitan diantaranya mahasiswa menghafal rumus dan teorema tanpa memahami konsep dasar jarak dan definisi nilai mutlak; mahasiswa terbiasa menggunakan rumus cepat sebagai bekal untuk masuk perguruan tinggi. Saran penelitian yakni dosen yang akan mengajarkan nilai mutlak harus menanamkan pentingnya konsep dasar dan melakukan pembiasaan pembelajaran konstruktivistik.

Keyword : Kesulitan, open ended, nilai mutlak, persamaan, pertidaksamaan

\begin{abstract}
The purpose of this study is to identify the types and factors causing student difficulties in solving mathematical problems based on open-ended material absolute value in the form of equations, inequalities, and provide advice for lecturers. The subjects of the study consisted of 138 students of PGSD UMSIDA in the basic mathematics concepts course, academic year 2016-2017. The research method used is qualitative descriptive. The research instrument consists of an Absolute Knowledge Test Sheet and interview guidance. Based on the data, the types of student difficulties include not being able to fully apply the concept of distance and the definition of absolute value so that the completion step is not complete; experiencing a misunderstanding of absolute value terms; experiencing misconceptions in the form of assumption that absolute value is always positive; have difficulty in terms of conceptual, procedural, and algorithm. The factors that cause difficulties include students memorizing formulas and theorems without understanding the basic concepts of distance and definition of absolute value; students are accustomed to use the quick formula as a provision to enter college. It can be suggested that lecturers who will teach the absolute value must instill the importance of basic concepts and do habituation constructivist learning.
\end{abstract}

Keywords: difficulties, open ended problem, absolute value, equations and inequalities

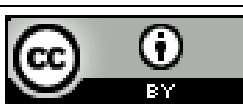

$\mathrm{W}:$ http://ejurnal.mercubuana-yogya.ac.id/index.php/mercumatika E : mercumatika@mercubuana-yogya.ac.id

DOI: http://dx.doi.org/10.26486/jm.v2i2.291 


\section{PENDAHULUAN}

Matematika sampai sekarang dianggap oleh siswa atau mahasiswa sebagai matapelajaran yang sulit untuk dipelajari. Dalam hal ini pendidik di segala jenjang memiliki tanggung jawab besar untuk memperbaikinya. Hal mendasar yang dapat dilakukan adalah mengidentifikasi kesulitan peserta didik untuk dicarikan solusi dan dilakukan tindakan, tidak terkecuali pula di tingkat perguruan tinggi. Oleh karena itu penelitian mengenai identifikasi kesulitan atau kesalahan mahasiswa pada materi tertentu di matakuliah matematika selalu penting dan menarik untuk dilakukan sebagai bahan evaluasi untuk memperbaiki kualitas perkuliahan.

Salah satu materi dalam matematika adalah nilai mutlak, materi ini dirasa sulit oleh mahasiswa sekalipun karena banyak sekali ditemukan kesulitan yang beragam pada pekerjaan mereka. Sebagaimana beberapa penelitian terdahulu oleh Ciltas dan Tatar (2011) yang menemukan bahwa mahasiswa mengalami kesulitan dalam menemukan solusi yang tepat, mereka menyelesaikan soal seolah-olah tidak ada nilai mutlak dalam persamaan dan pertidaksamaan yang diberikan, dan tidak dapat sepenuhnya mengaplikasikan konsep nilai mutlak dalam penyelesaiannya.

Dalam materi persamaan dan pertidaksamaan pun, seringkali mahasiswa mengalami kesulitan, hasil penelitian Amir (2015) menyimpulkan mahasiswa mengalami kesalahan konsep, prinsip, dan operasi dalam menyelesaikan soal pertidaksamaan linier. El- khateeb (2016) menemukan beberapa mahasiswa mengalami misconceptions (kesalahpahaman) dan misunderstanding (ketakpahaman) dalam memecahkan masalah pertidaksamaan. Dari penelitianpenelitan tersebut diketahui mahasiswa memiliki kesulitan yang beragam dalam menyelesaikan soal yang berkaitan dengan nilai mutlak bentuk persamaan dan pertidaksamaan. Menurut Usman, Hasbi, dan Bambang (2015) pemahaman prinsip dasar pertidaksamaan nilai mutlak penting bagi calon guru agar tidak mengalami misunderstanding matematika. Berdasarkan hasil evaluasi tes pada materi nilai mutlak persamaan dan pertidaksamaan peneliti pada matakuliah konsep dasar matematika dari 138 mahasiswa PGSD diperoleh bahwa 94 (68\%) mahasiswa memiliki kategori nilai di bawah B. Hasil ini menunjukkan mahasiswa mengalami kesulitan. Oleh karena itu, peneliti sebagai dosen pengampu tertarik mengidentifikasi lebih lanjut kesulitan mahasiswa dalam memecahkan masalah nilai mutlak bentuk persamaan dan pertidaksamaan, sekaligus memberikan saran bagi para pendidik (dosen) di perguruan tinggi.

\section{METODE}

Metode penelitian yang digunakan adalah deskriptif kualitatif. Penelitian ini dilaksanakan di PGSD FKIP Universitas Muhammadiyah Sidoarjo pada bulan November tahun 2016 semester I (gasal), subjek penelitian adalah 138 mahasiswa di kelas A1, A2, A3, dan A4 yang memprogram matakuliah konsep dasar matematika. Instrumen terdiri dari Lembar Tes Pengetahun Nilai Mutlak (LTPNM) berbasis open ended dan pedoman wawancara. LTPNM diadaptasi dari Horak (dalam Ciltas dan Tatar,

2011).

\section{HASIL DAN PEMBAHASAN}

Frekuensi dan persentase jawaban mahasiswa dari Lembar Tes Pengetahuan Nilai Mutlak (LTPNM) bentuk persamaan dan pertidaksamaan yang diklasifikasikan dalam benar, salah, dan tidak dijawab dapat dilihat pada Tabel 1. Analisis hasil LTPNM dan transkrip wawancara subjek 
penelitian dilakukan dengan mengidentifikasi setiap nomor dan pasangan nomor yang memiliki penyelesaian identik.

Tabel 1. Persentase Jawaban Mahasiswa Pada LTPNM.

\begin{tabular}{ccccccccccc}
\hline \multirow{2}{*}{ Jawaban } & \multicolumn{10}{c}{ Pertanyaan } \\
\cline { 2 - 11 } & P1 & P2 & P3 & P4 & P5 & P6 & P7 & P8 & P9 & P10 \\
\hline $\begin{array}{c}\text { Benar } \\
(\%)\end{array}$ & 87 & 90 & 0 & 15 & 0 & 0 & 21 & 23 & 0 & 0 \\
\hline Salah & 51 & $46)$ & $(0)$ & $(11)$ & $(0)$ & $(0)$ & $(15)$ & $(17)$ & $(0)$ & $(0)$ \\
$(\%)$ & $(37)$ & $(33)$ & $(94)$ & $(85)$ & $(83)$ & $(86)$ & $(85)$ & $(81)$ & $(98)$ & $(33)$ \\
\hline $\begin{array}{c}\text { Tidak } \\
\text { dijawab } \\
(\%)\end{array}$ & 0 & 2 & 8 & 6 & 23 & 19 & 0 & 3 & 3 & 92 \\
$(0)$ & $(2)$ & $(6)$ & $(4)$ & $(17)$ & $(14)$ & $(0)$ & $(2)$ & $(2)$ & $(67)$
\end{tabular}

Keterangan:

P1-P10 = Pertanyaan nomor 1 sampai nomor 10 pada LTPNM

\section{Nomor 1}

Soal nomor 1 adalah soal yang berbentuk $|f(x)|=a$ yang memiliki banyak strategi penyelesaian, diantaranya menggunakan konsep jarak yang merupakan konsep dasar nilai mutlak. Jadi jika mahasiswa tidak dapat menggunakan strategi tersebut dapat dipastikan pemahaman mahasiswa kurang baik. Pada jawaban salah, sebanyak 20 (40\%) mahasiswa menjawab dengan bentuk seperti Gambar 1.

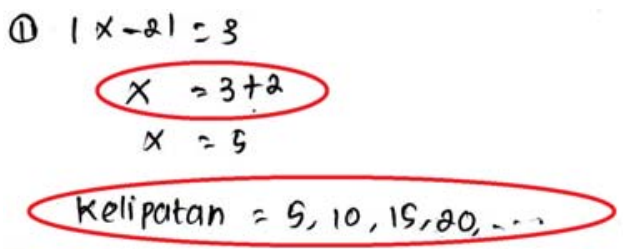

Gambar 1. Jawaban mahasiswa berkode VL pada nomor 1

Berikut ini diberikan transkrip hasil wawancara dengan mahasiswa berkode VL yang memberikan jawaban tersebut.

P: "bagaimana strategimu nomor 1?"

VL: "harga $|x-2|$ selalu positif sehingga bisa langsung disederhanakan"

P: "bagaimana caranya?"

VL: " $|x-z|=3$ menjadi $x-2=3$ kemudian -2 saya pindah ruas, jadi didapatkan $x=5$ "

P: "bagaimana kamu yakin??"

VL: "mensubstitusikan nilai $\mathrm{x}=5$ ke persamaan awal.

P: "apakah kamu benar-benar sudah mendapatkan jawaban yang diminta?"

VL: "belum saya lupa, tapi jawabannya adalah kelipatannya itu 5,10,15, ...."

P: "adakah cara lain?"

VL: "ada, kuadratkan ke-2 ruas".

Dari uraian tersebut dapat diperoleh penjelasan bahwa strategi yang digunakan mahasiswa berkode VL untuk memecahkan masalah adalah mengangap $|x-2|$ selalu bernilai positif sehingga mahasiswa dapat langsung mencari nilai $x$ dengan memindahkan -2 ke ruas lainnya. Mahasiswa berkode VL yakin dengan jawaban yang diperoleh dengan mensubstitusikan $x=5 \mathrm{ke}$ 
persamaan $|x-z|$. Memang jawaban $x=5$ benar karena ketika di cek dengan memasukkannya ke persamaan awal akan didapatkan $3=3$. Tapi mahasiswa berkode VL tidak mengetahui bahwa ada kemungkinan jawaban selain $x=5$, karena definisi nilai mutlak yang digunakannya salah. Dari wawanca dapat diketahui bahwa mahasiswa VL mengetahui ada cara lain yakni "mengkuadratkan ke-2 ruas", tapi dia tidak menggunakan cara tersebut. Mahasiswa berkode VL tidak mengetahui konsep jarak pada nilai mutlak sebagai konsep dasar.

Pada jawaban benar secara tertulis mengisyaratkan bahwa mahasiswa mengalami miskonsepsi definisi nilai mutlak, sebanyak 74 (85\%) jawaban benar dalam bentuk seperti dibawah ini, sisanya mahasiswa menggunakan cara dengan konsep jarak.

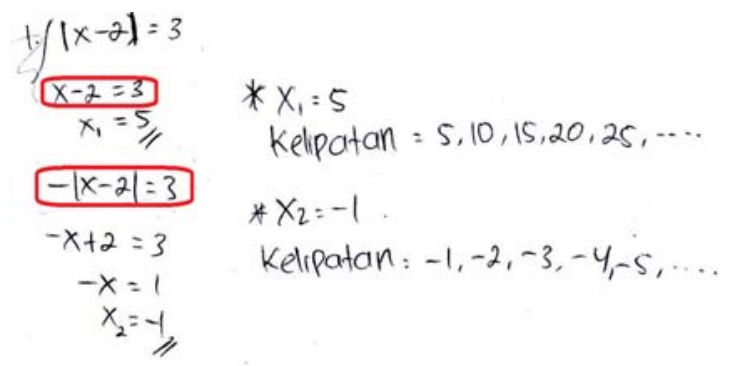

Gambar 2. Jawaban mahasiswa berkode LM pada nomor 1

Berikut diberikan transkrip hasil wawancara dengan mahasiswa berkode LM yang memberikan jawaban benar.

P: "bagaimana strategimu?"

LM: "karena $|x-2|$ dapat bernilai positif dan negatif, jadi nanti ada 2 kemungkinan jawaban."

P: “jelasakan penyelesaianmu?"

LM: "pertama $|x-2|$ positif menjadi $x-2=3$ dengan memindah -2 ke ruas kanan, saya dapatkan $x_{1}=5$. Kedua $|x-2|$ bernilai negatif menjadi $-x+2=3$ dengan memindah 2 ke ruas kanan, saya dapatkan $\mathrm{x}_{2}=\mathbf{- 1}$. Jadi bisa didapatkan kelipatannya."

P: "Yakin benar? Caranya?"

LM: "mensubstitusikan $\mathrm{x}_{1}=\mathbf{5}$ dan $\mathrm{x}_{2}=-1$ ke persamaan $|\mathrm{x}-2|=3$ "

P: "kira-kira ada tidak syarat yang tertinggal?"

LM: "tidak."

Dari uraian di atas dapat diperoleh penjelasan bahwa meskipun jawaban secara tertulis yang diberikan mahasiswa berkode LM benar, tapi strategi yang digunakan ada kesalahan mengenai definisi nilai mutlak yakni mahasiswa tidak memperhitungkan batasan nilai $x$ yang ada pada setiap kemungkinan. Sebetulnya, syarat pada kemungkinan pertama adalah $x \geq 2$ dan pada kemungkinan kedua adalah $r<2$. Jika konsep nilai mutlak yang dimiliki mahasiswa demikian, ada kemungkinan jawaban mahasiswa akan salah untuk soal dalam bentuk lainnya.

Mahasiswa berkode VL dan berkode LM sama-sama tidak dapat menggunakan strategi konsep jarak dalam bentuk soal $|f(x)|=a$. Hal ini menunjukkan pemahaman siswa masih sangat rendah. Jika mahasiswa tidak memahami konsep dasar tersebut, maka bukan tidak mungkin mahasiswa akan kesulitan memecahkan masalah lain yang lebih kompleks.

\section{Nomor 2 dan Nomor 4}

Meskipun soal nomor 2 dan nomor 4 memiliki bentuk nilai mutlak yang sama yakni $|f(x)|=|g(x)|$, akan tetapi ada hal yakni misunderstanding (ketidakpahaman) mahasiswa 
mengenai konsep nilai mutlak semakin terlihat. Berikut dijelaskan perbedaan kesulitan menjawabnya. Pada jawaban yang salah, rata-rata 47\% mahasiswa menjawab seperti gambar 3 .

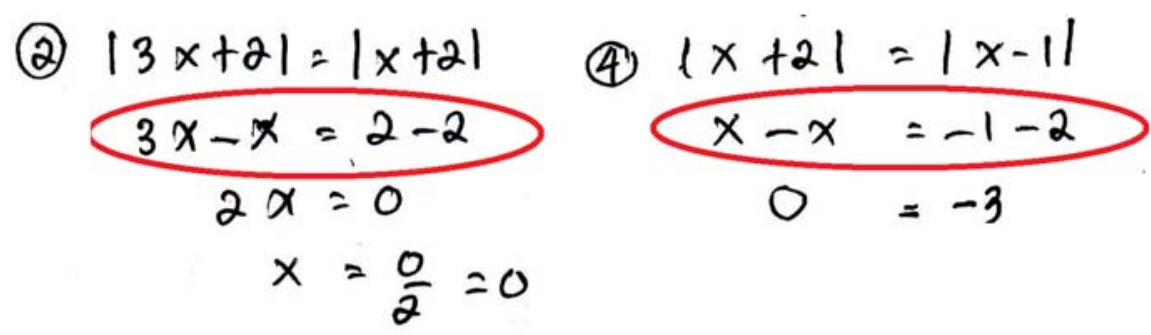

Gambar 3. Jawaban mahasiswa berkode VL pada nomor 2 dan nomor 4

Berikut diberikan transkrip hasil wawancara dengan mahasiswa VL.

P: “jelaskan strategimu untuk menyelesaikan soal nomor 2?"

VL: " $|3 x+2|$ dan $|x+2|$ ada pada ruas kiri dan kanan jadi bisa langsung harga mutlaknya dihilangkan."

P: "ya terus langkah penyelesaiannya?"

VL: “ $|3 x+z|$ menjadi $3 x+z$ dan $|x+2|$ menjadi $x+2$, kemudian -x saya pindah ruas kiri dan 2 saya pindah ruas kanan. Dengan $3 \mathrm{x}-\mathrm{x}$ dan $2-2=0$, kemudian $\frac{0}{2}=0$. Sehingga didapatkan $\mathrm{x}=\mathbf{0}$."

P: "yakin dengan jawabanmu benar?"

VL: "ya dengan mensubstitusikan nilai $x=0$ ke persamaan awal"

P: “apakah kamu yakin sudah mendapatkan jawaban benar?"

VL: "ya, kan jawabannya hanya 0 sehingga jumlahan x nya juga $0 . "$

P: "adakah cara lain?"

VL: "ada, dikuadratkan ke-2 ruas, tapi saya menggunakan cara ini karena lebih cepat"

P: "kemudian pada nomor 4?"

VL: "karena nomor 4 dan 4 bentuknya sama, jadi ya caranya sama."

P: "perbedaannya apa?"

VL: "pada nomor 2 saya bisa mendapatkan nilai x nya tapi nomor 4 tidak."

P: "jadi kira-kira jawabannya gimana?"

VL: "mungkin $\emptyset "$.

P: "coba cek apa benar?"

VL: (mahasiswa menghitung di kertas) "iya pak beda $2 \neq 1 . "$

P: “dengan cara pada nomor 4 , jawabannya $2 \neq 1$. Jadi apakah caramu pada nomor 4 dan 2 benar?"

VL: "ya mungkin salah, gak tau pak."

Dari uraian di atas dapat diperoleh penjelasan bahwa strategi yang digunakan mahasiswa berkode VL untuk menyelesaikan soal adalah mengangap tidak ada nilai mutlak pada persamaan $|3 \mathrm{x}+2|=|\mathrm{x}+2|$ sehingga mahasiswa dapat langsung mencari nilai $x$ dengan memindahkan variabel $x$ ke ruas kiri dan konstanta keruas kanan untuk mencari nilai $x$ yang memenuhi. Mahasiswa berkode VL yakin dengan jawaban yang diperoleh dengan mensubstitusikan $x=0$ ke persamaan awal. Memang jawaban $x=0$ benar karena ketika di cek dengan memasukkannya ke persamaan awal sehingga didapatkan $0=0$. Tapi mahasiswa berkode VL tidak mengetahui bahwa 
Vol. 2, No. 1, Oktober 2017, pp. 1-15

ada kemungkinan jawaban lain selain $x=0$, karena konsep yang digunakan dengan menghilangkan nilai mutlak pada persamaan bentuk $|f(x)|=|g(x)|$ salah.

Dari wawancara dapat diketahui bahwa mahasiswa berkode VL mengetahui ada cara lain untuk menyelesaikan soal selain menggunakan cara "menghilangkan nilai mutlak" yakni "dikuadratkan ke-2 ruas", tapi dia tidak menggunakan cara tersebut dengan alasan tidak cepat. Mahasiswa berkode VL juga menggunakan strategi yang sama untuk menyelesaikan soal nomor 4, akan tetapi perbedaannya pada nomor 4 tidak dapat mendapatkan nilai $x$ nya. Sehingga mahasiswa berkode VL berpendapat nilai $x$ nya adalah $\emptyset$. Saat diberikan pertanyaan melalui wawancara untuk mengecek apakah cara yang digunakan pada nomor 2 dan nomor 4 dengan mensubstitusikan $x=\emptyset$ ke persamaan awal, mahasiswa berkode VL baru menyadari bahwa jawaban dan konsep yang digunakan salah. berikut ini.

Jawaban mahasiswa lain dari pasangan nomor 2 dan nomor 4 ditunjukkan pada gambar 4

$$
\text { 2.). } \begin{aligned}
& |3 x+2|=|x+2| \\
& (3 x+2)^{2}=(x+2)^{2} \\
& 9 x^{2}+12 x+4=x^{2}+4 x+4 \\
& 9 x^{2}+12 x+4-x^{2}-4 x-4=0 \\
& 8 x^{2}+8 x=0 \\
& 8 x(x+1)=0 \\
& 8 x=0 \quad V x+1=0 \\
& x_{1}=0 \quad x_{2}=-1 \\
& \therefore \text { Jumlah } x_{1} \text { dan } x_{2} \\
& \Rightarrow 0+(-1)=-1
\end{aligned}
$$

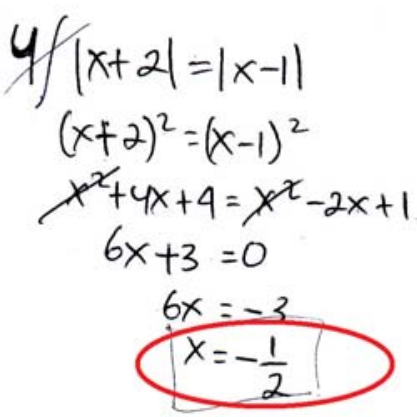

Gambar 4. Jawaban mahasiswa berkode LM pada nomor 2 dan nomor 4

Berikut ini diberikan transkrip hasil wawancara mahasiswa berkode LM.

P: “jelaskan strategimu?

LM: "saya mengkuadratkan ke-2 ruas kemudian saya manipulasi dengan memisahkan variabel $\mathrm{x}$ dan yang tidak memiliki variabel pada masing-masing ruas, saya faktorkan sehingga dapat kedua nilai x."

P: "jadi strategi nomor 2 dan 4 sama?"

LM: "sama."

P: "bagaimana kamu yakin?"

LM: “memasukkan x yang diperoleh ke persamaan sebelumnya, untuk nomor 2 saya masukkan 0 ke $|3 x+2|=|x+2|$ diperoleh $2=2$, kemudian -1 diperoleh $1=1$. Untuk nomor 4 saya masukkan $\mathrm{x}=-\frac{1}{2}$ ke persamaan $|\mathrm{x}+2|=|\mathrm{x}-1|$ diperoleh $\frac{3}{2}=\frac{3}{2}$."

P: "Pada nomor 4 benarkah $\mathrm{x}=-\frac{1}{2}$ ?"

LM: "ehm... iya."

P: “coba yang diminta kan himpunan, apakah $\mathrm{x}=-\frac{1}{2}$ himpunan?"

LM: "salah sepertinya yang benar $\left\{-\frac{1}{2}\right\}$.

P: "adakah cara lain?"

LM: "definisi, tapi cara ini lebih cepat." 
P: "kenapa?"

LM: "kalo menggunakan definisi banyak kemungkinannya, saat bimbel saya dulu diajarkan biar lebih cepat."

Dari uraian di atas dapat diperoleh penjelasan bahwa strategi yang digunakan mahasiswa berkode LM untuk menyelesaikan soal nomor 2 adalah mengkuadaratkan ke-2 ruas untuk mengelompokkan variabel dan konstanta pada ruas yang berbeda, kemudian memfaktorkan agar mendapatkan ke-2 nilai $x$ dan menjumlahkannya.

Stratagi yang sama digunakan pada nomor 4, hanya perbedaannya pada nomor 4 mahasiswa berkode LM salah dalam menuliskan jawaban akhir yakni $x=-\frac{\vdots}{2}$, padahal seharusnya jawabannya adalah himpunan $x$ yang bernilai $-\frac{1}{2}$ atau HP $=\left\{-\frac{1}{2}\right\}$. Mahasiswa berkode LM baru menyadari kesalahannya saat dilakukan wawancara. Mahasiswa berkode LM yakin dengan jawabannya karena setelah mensubstitusikan nilai $x$ ke persamaan diperoleh bilangan sama di kedua ruas.

Dari wawancara dapat diketahui bahwa mahasiswa berkode LM mengetahui ada cara lain untuk menyelesaikan soal selain "dikuadratkan ke-2 ruas" yakni dengan menggunakan definisi nilai mutlak, tapi dia tidak menggunakan cara tersebut dengan alasan tidak cepat untuk mengikuti seleksi masuk perguruan tinggi.

Jawaban mahasiswa salah yang lain pada nomor 2 dan 4 ditunjukkan pada Gambar 5.

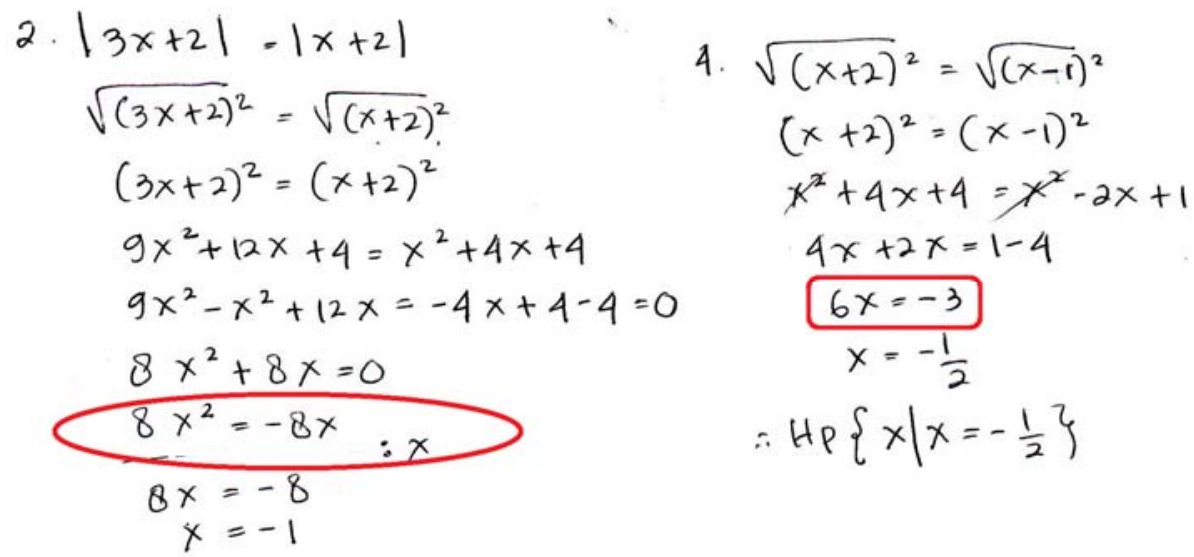

Gambar 5. Jawaban mahasiswa berkode AE pada nomor 2 dan nomor 4

Berikut ini diberikan transkrip hasil wawancara pada mahasiswa berkode AE yang memberikan jawaban tersebut.

P: “jelaskan strategi nomor 2?"

AE: "karena $\sqrt{\mathrm{x}^{2}}=|\mathrm{x}|$, maka saya bisa mengatakan $|3 \mathrm{x}+2|=\sqrt{(3 \mathrm{x}+2)^{2}}$ dan begitu pula $|x+2|$. Kemudian dengan menyederhanakan ke-2 ruas saya bisa mendapatkan nilai x."

P: “ok, bagaimana langkahnya?"

AE: $\quad$ " $|3 x+2|=|x+2|$ dari itu tadi didapatkan $\sqrt{(3 x+2)^{2}}=\sqrt{(x+2)^{2}}$, saya kuadratkan menjadi $(3 \mathrm{x}+2)^{2}=(\mathrm{x}+2)^{2}$. Kemudian saya kelompokkan menjadi $9 x^{2}-x^{2}+12 x=-4 x+4-4$, saya sederhanakan menjadi $8 x^{2}=-8 x$ terus saya bagi $\mathrm{x}$, saya bagi dengan -8 maka mendapat $\mathrm{x}=-1$."

P: "langkah yang $8 \mathrm{x}^{2}+8 \mathrm{x}=0$, kenapa jadi $8 \mathrm{x}^{2}=-8 \mathrm{x}$ ?"

AE: "supaya mudah membagi dengan $\mathrm{x} . "$

P: "apakah tidak ada selain $\mathrm{x}=-1$ ". 
AE: "iyaa... mungkin tidak ada."

Vol. 2, No. 1, Oktober 2017, pp. 1-15

P: "buktinya?"

AE: "Langkah yang saya kerjakan sudah benar tapi saya tidak tau buktinya.

P: "bagaimana cara untuk nomor 4?"

AE: "hampir sama kan bentuknya sama.

P: "adakah cara lain?"

AE: "mungkin ada."

P: "dari mana kamu dapatkan cara itu?

AE: "dari tempat les saya dulu."

Dari uraian di atas dapat diperoleh penjelasan bahwa strategi yang digunakan mahasiswa berkode AE pada soal nomor 2 adalah membawa bentuk $|f(x)|=|g(x)|$ ke dalam bentuk $\sqrt{(f(x))^{2}}=\sqrt{(g(x))^{2}}$ untuk dikuadratkan, dikelompokkan variabel dan konstantannya kemudian disederhanakan. Pada langkah mahasiswa berkode AE terdapat kesalahan konsep dalam memfaktorkan persamaan yang didapat. Mahasiswa berkode AE malah merubah persamaan $8 x^{2}+8 x=0$ ke dalam $8 x^{2}=-8 x$ untuk kemudian dibagi dengan $x$.

Pada nomor 4 mahasiswa berkode AE menggunakan cara yang sama, akan tetapi mahasiswa berkode AE tidak menemui kesalahan karena pada akhir langkah untuk mendapatkan nilai $x$ pembagian yang ada berbentuk $6 x=-3$ dibagi dengan 3 di kedua ruas menjadi $x=-\frac{1}{2}$. Mahasiswa berkode AE tidak mampu untuk membuktikan jawabannya benar atau salah dan menggunakan cara penyelesaian selain "dikuadratkan ke-2 ruas" karena pada tempat lesnya dulu diajari cara tersebut untuk dapat lolos seleksi SBMPTN.

\section{Nomor 5 dan nomor 6}

Soal nomor 5 dan nomor 6 merupakan pasangan nomor yang memiliki bentuk $|f(x)|+a=|g(x)|+b$ dapat diamati bahwa tidak ada mahasiswa yang menjawab dengan benar dan rasio jawaban mahasiswa yang salah adalah sangat tinggi (rata-rata $85 \%$ ), serta banyak sekali kesalahan mahasiswa yang cukup kompleks dan beragam. Hal ini menyiratkan bahwa meskipun nomor 5 dan nomor 6 memiliki bentuk yang sama, akan tetapi soal nomor 5 dirasa lebih sulit bagi mahasiswa. Sebanyak $41 \%$ dari jawaban mahasiswa yang salah pada nomor 5 dan nomor 6 memiliki bentuk sebagai berikut.

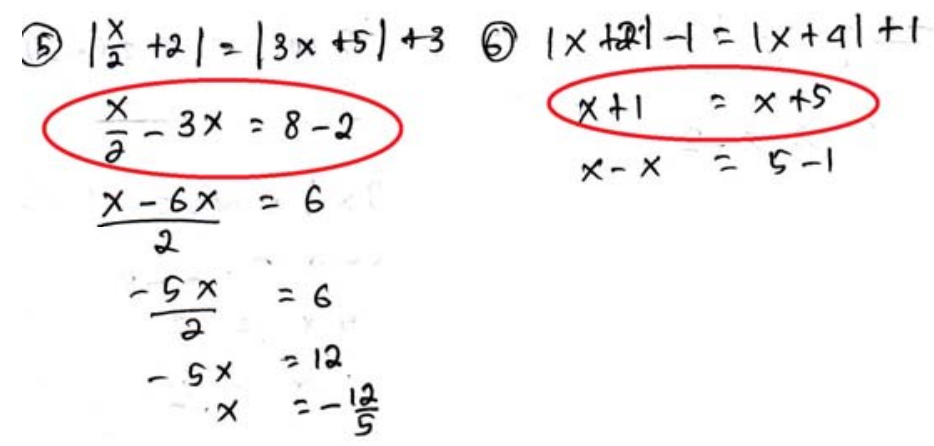

Gambar 6. Jawaban mahasiswa berkode VL pada nomor 5 dan nomor 6

Berikut transkrip hasil wawancara dengan mahasiswa berkode VL.

P: "bagaimana strategi nomor 5 dan 6?"

VL: "semua nilai mutlak bernilai positif"

P: "berapa penyelesaian nomor 6?"

VL: "saya tidak tau, seperti nomor 4."

P: "kenapa?" 
VL: "seperti sebelum, himpunan kosong"

P: "ada cara lain dan bagaimana?"

VL: "dikuadratkan ruas, tapi tidak bisa".

Dari uraian di atas dapat diperoleh penjelasan bahwa strategi yang digunakan mahasiswa berkode VL untuk menyelesaikan soal nomor 5 dan nomor 6 adalah sama seperti pekerjaannya pada nomor 1 yakni mengangap nilai mutlak pada persamaan selalu bernilai positif. Hal ini menunjukkan adanya konsistensi kesulitan mahasiswa berupa misunderstanding definisi nilai mutlak. Hal ini cukup fatal pada materi nilai mutlak karena nilai mutlak tidak hanya bernilai positif tapi bernilai negatif, serta ada syarat-syarat pada setiap kemungkinannya yang harus diperhatikan. Jika mahasiswa memiliki kesulitan sama seperti mahasiswa berkode VL, hampir dipastikan mahasiswa akan mengalami kesulitan dalam memecahkan masalah lain. Mahasiswa berkode VL juga tidak mengetahui cara "dikuadratkan ke-2 ruas" pada soal berbentuk $|f(x)|+a=|g(x)|+b$.

Sebagian besar jawaban mahasiswa yang salah pada pasangan nomor 5 dan nomor 6 seperti pada Gambar 7.
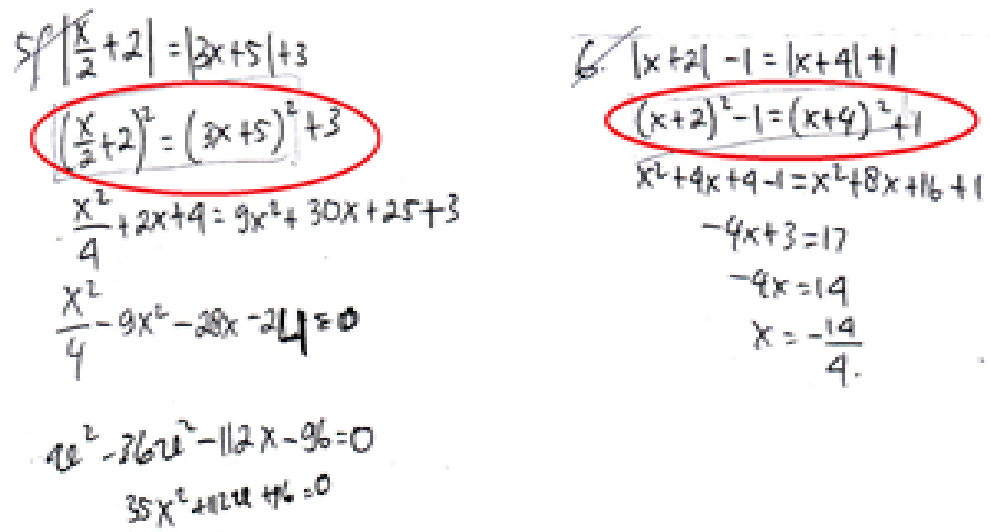

Gambar 7. Jawaban mahasiswa berkode LM pada nomor 5 dan nomor 6

Berikut ini diberikan transkrip hasil wawancara dengan mahasiswa berkode LM yang memberikan jawaban tersebut.

P: “jelaskan strategi nomor 5 dan 6?"

LM: "saya kuadratkan nilai mutlaknya agar bernilai positif, nilai kalau tidak dikuadratkan nanti bernilai negatif dan positif."

P: "kenapa yang dikuadratkan hanya itu? Tapi $\mathbf{- 1}$ dan 1 tidak ikut?"

LM: "supaya mudah saja yang penting nilai mutlaknya positif dulu."

P: "apa kamu tidak tau cara lain?"

LM: “definisi nilai mutlak tapi saya bingung mengerjakannya karena banyak kemungkinannya."

P: "pada nomor 5 kenapa tidak kamu selesaikan pemfaktorannya?"

LM: "saya bingung."

P: "pada nomor 6, bagaimana kamu yakin jawabanmu benar?"

LM: "dimasukkan $\mathrm{x}=-\frac{14}{4}$ ",

P: “jadi kira-kira caramu tadi benar?"

LM: "gak tau."

Dari uraian di atas dapat diperoleh penjelasan bahwa strategi yang digunakan mahasiswa berkode LM untuk menyelesaikan soal nomor 5 dan nomor 6 berbentuk $|f(x)|+a=|g(x)|+b$ adalah mengkuadratkan nilai mutlaknya saja agar nilai mutlaknya bernlai positif. Mahasiswa 
Vol. 2, No. 1, Oktober 2017, pp. 1-15

berkode LM menggunakan cara tersebut karena berpendapat cara yang digunakannya sama dengan bentuk $|f(x)|=|g(x)|$ pada nomor 2 dan tidak dapat menggunakan cara definisi nilai mutlak yang nantinya memunculkan berbagai kemungkinan solusi. Hal ini menunjukkan meskipun jawaban mahasiswa berkode LM benar pada nomor 2 yang berbentuk $|f(x)|=|g(x)|$, sebetulnya siswa tidak memahami (misunderstanding) konsep "dikuadratkan ke-2 ruas" pada persamaan nilai mutlak, persamaan linier satu variabelnya dan konsep nilai mutlak itu sendiri.

Hal tersebut menunjukkan juga bahwa mahasiswa berkode LM hanya menghafal konsep dan langkah-langkah prosedural bentuk $|f(x)|=|g(x)|$ untuk dikuadratkan saat berada di Lembaga Bantuan Belajar (LBB) agar lolos seleksi perguruan tinggi. Saat diminta untuk memfaktorkan jawaban akhir yang diperoleh pada nomor 5, mahasiswa berkode LM tidak mampu melakukannya. Mahasiswa berkode LM juga baru menyadari jika jawaban nomor 6 salah saat diminta peneliti untuk mengeceknya.

\section{Nomor 3 dan Nomor 9}

Soal nomor 3 dan nomor 9 merupakan pasangan nomor berbentuk $|f(x)|=g(x)$ yang identik dengan soal berbentuk $|f(x)|+a=|g(x)|+b,\left|\frac{-a}{f(x)}\right| \geq a$. Namun berbeda dengan soal berbentuk $|f(x)|=|g(x)|,|f(x)|<a$, atau $|f(\mathrm{x})|>a$ yang sangat memungkinkan mahasiswa dapat menentukan himpunan penyelesaiannya dengan benar, meskipun mahasiswa tidak paham dengan baik konsep nilai mutlak. Pada soal berbentuk $|f(x)|=g(x)$ tidak akan terjadi hal demikian, karena meskipun menggunakan cara definisi atau "dikuadratkan ke-2 ruas", mahasiswa harus memperhitungkan syarat atau batasan solusinya. Jadi hasil pekerjaan soal berbentuk $|f(x)|=g(x)$ dapat lebih memberikan informasi kesulitan dalam hal konseptual, prosedural, ataupun lainnya pada mahasiswa.

Persentase kesalahan pada pasangan nomor 3 dan nomor 9 adalah yang tertinggi yakni 96\%. Hal itu menunjukkan bahwa mahasiswa kesulitan menyelesaikan soal bentuk ini, artinya kemampuan siswa sebenarnya dalam menyelesaikan soal nilai mutlak masih banyak terdapat kesulitan dalam hal konseptual, prosedural, atau algoritmanya. Sebagian besar jawaban mahasiswa salah pada nomor 3 dan nomor 9 berbentuk seperti pada Gambar 8 .
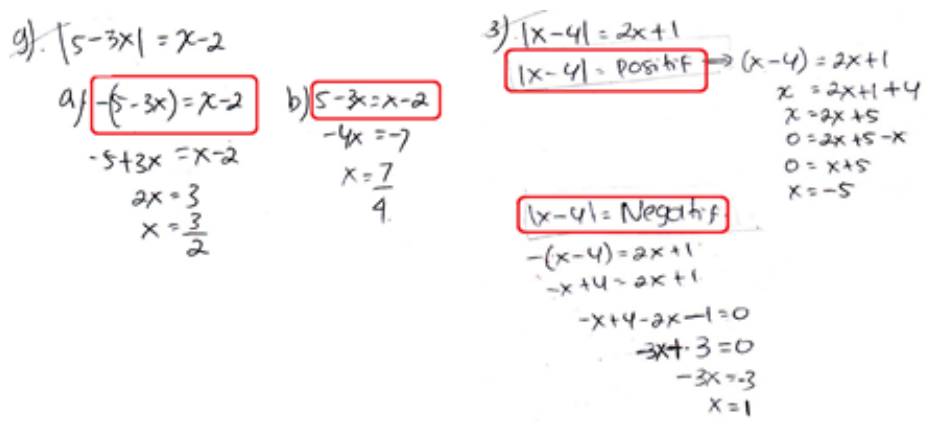

Gambar 8. Jawaban mahasiswa berkode LM pada nomor 3 dan nomor 9

Berikut diberikan transkrip wawancara mahasiswa berkode LM

P: “jelaskan caramu pada nomor 3?"

LM: "harga mutlak dapat bernilai positif dan negatif"

P: " $2 \mathrm{x}+1$ tidak berubah nilanya?"

LM: "tidak memiliki nilai mutlak."

P: "kalo jawabanmu?"

LM: “yakin."

P: "coba cek? Kan $x$ nya -5 dan 1" 
LM: "tidak sama, yang sama $\mathrm{x}=1$ "

P: "langkah penyelesaianmu kan benar, berarti strategimu ada yang salah."

LM: "(mahasiswa diam)"

P: "samakah strategi dan langkah penyelesaianmu untuk nomor 9?"

LM: "sama."

P: "coba cek juga jawabanmu?

LM: "tidak sama"

P: " "jika menggunakan dikuadratkan ke-2 ruas adakah syarat lain?."

LM: "tidak ada."

Dari uraian di atas dapat diperoleh penjelasan bahwa strategi yang digunakan mahasiswa berkode LM untuk menyelesaikan soal nomor 3 dan nomor 9 adalah sama seperti pekerjaannya pada nomor 1 yakni tidak memperhatikan syarat yang ada untuk setiap kemungkinannya. Hal ini menunjukkan adanya konsistensi kesulitan mahasiswa dalam memecahkan masalah pada definisi nilai mutlak. Mahasiswa berkode LM juga, mahasiswa tidak memperhitungkan syarat yang ada sebagai solusinya. Berbeda pada soal berbentuk $|f(x)|=a$, meskipun pemahaman konsep mahasiswa berkode LM salah. Akan tetapi jawabannya tetap benar karena syaratnya tidak mempengaruhi nilai $x$ yang didapatnya.

\section{Nomor 7 dan Nomor 8}

Solusi penyelesaian dari pasangan soal nomor 7 dan nomor 8 dapat menggunakan secara langsung teorema yang berlaku pada nilai mutlak. Strategi soal nomor 7 berbentuk $|f(x)| \alpha_{\text {n }} a$ menggunakan $-a<f(x)<a$, sementara strategi soal nomor 8 yang berbentuk $|f(x)|>a$ yang strategi penyelesaiannya menggunakan $f(x)>a v f(x)<-a$.

Kesalahan mahasiswa pada pasangan nomor ini memiliki rasio yang tinggi yakni rata-rata $83 \%$, Hal tersebut nampak pada hasil pekerjaan dan traskrip wawacara mahasiswa. Hampir keseluruhan mahasiswa menjawab nomor 7 dan nomor 8 seperti pada Gambar 9.
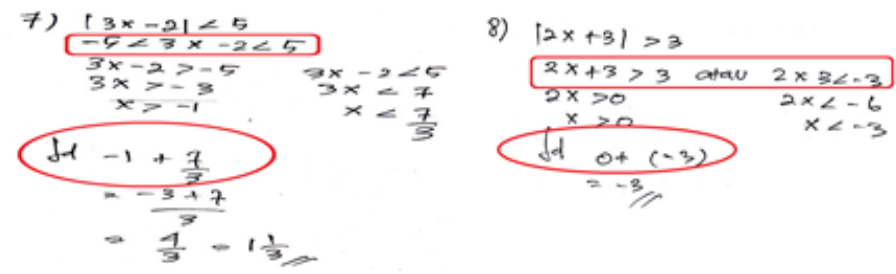

Gambar 9. Jawaban mahasiswa berkode LM pada nomor 7 dan nomor 8

Berikut ini diberikan transkrip wawancara mahasiswa berkode UA

P: "bagaimana mencari himpunan penyelesaian nomor 7 dan 8 ?"

LM: "menggunakan rumus."

P: "maksudnya?

LM: "dari $|3 \mathrm{x}-2|<5$ menjadi $-5<3 \mathrm{x}-2 \propto 5$."

P: "kenapa bisa begitu."

LM: "pokonya begitu"

P: "dari LBB dulu?"

LM: "iya."

P: "untuk yang nomor $8 ? "$

LM: "juga rumus $|2 x+3|>3$ menjadi $2 x+3>3$ atau $2 x+3<3$ " 
P: "yakin dengan jawabanmu $1 \frac{1}{3}$ ?

Vol. 2, No. 1, Oktober 2017, pp. 1-15

LM: "dijumlahkan $-1+\frac{7}{3}$ "

P: "Bukankah yang diminta nilai bilangan bulat?"

LM: "ya."

P: "terus kenapa ada pecahan."

LM: "gak tau pak bingung saya."

P: "untuk nomor 8 juga, kenapa 0 dan -3 yang dijumlahkan?"

LM: "itu bilangan bulatnya."

P: "termasuk gak dalam intervalnya?"

LM: "tidak."

Dari uraian di atas dapat diperoleh penjelasan bahwa strategi yang digunakan mahasiswa berkode LM untuk menyelesaikan soal nomor 7 dan nomor 8 adalah menggunakan teorema secara langsung. Mahasiswa berkode LM mampu untuk menentukan himpunan penyelesaian, tapi tidak mampu untuk menentukan jawaban yang diminta dalam soal. Pada nomor 7 dan nomor 8 diminta untuk menentukan jumlah nilai bilangan bulat, siswa malah menjumlahkan batasan himpunan penyelesaiannya. Hal ini menunjukkan mahasiswa berkode LM tidak paham konsep (misunderstanding) interval pada pertidaksamaan bilangan real. Saat wawancara, mahasiswa menyadari bahwa jika menggunakan cara definisi nilai mutlak harus memperhitungkan syarat.

Fakta menarik yang dapat diamati lagi adalah mahasiswa berkode LM mampu untuk menentukan himpunan penyelesaian soal berbentuk $|f(x)|<a, \quad|f(x)|>a$ dengan menggunakan teorema yang didapatkan dari tempat bimbingan belajarnya, akan tetapi tidak mampu untuk menyelesaikannya menggunakan konsep dasar dan definisi nilai mutlak. Fakta ini terjadi seperti pada nomor 1, pasangan nomor 2 dan 4 yang menggunakan strategi "dikuadratkan ke-2 ruas".

\section{Nomor 10}

Soal nomor 10 berbentuk $\left|\frac{-a}{f(x)}\right| \geq \frac{1}{6}$, , berbeda dengan soal-soal sebelumnya. Pada soal ini mahasiswa harus dapat menentukan nilai mutlak yang berbentuk pecahan dan memahami perkalian atau memindah variabel pada ke-2 ruas dalam bentuk pertidaksamaan. Sementara itu tidak mungkin mahasiswa mampu menyelesaikannya, apabila tidak memahami konsep dasar nilai mutlak dan pertidaksamaan.

Pada Tabel 1 diperoleh informasi bahwa persentase jawaban mahasiswa yang tidak menjawab nomor 10 adalah yang paling tinggi $67 \%$ daripada nomor-nomor lain, serta tidak ada jawaban mahasiswa yang benar $0 \%$ dan jawaban mahasiswa yang salah 33\%. Persentase ini atas menunjukkan soal nomor 10 adalah soal yang paling dianggap sulit oleh mahasiswa, artinya banyak sekali kesulitan yang disebabkan kesalahan konseptual nilai mutlak dan pertidaksaan mahasiswa. Sebesar $74 \%$ dari jawaban mahasiswa yang salah pada nomor 10 berbentuk seperti pada gambar 10 berikut ini.

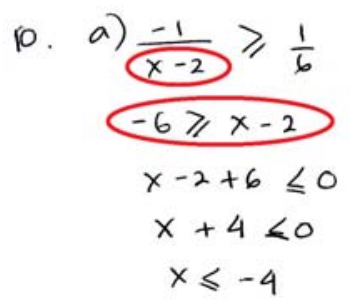
b) $\frac{-1}{x-2} \leqslant-\frac{1}{6}$$$
-6 \leqslant-x+2
$$$$
-x+2+6 \geqslant 0
$$$$
-x+8 \geqslant 0
$$$$
x \leqslant 8
$$

Gambar 10. Jawaban mahasiswa berkode AE pada nomor 10 
Berikut ini diberikan transkrip hasil wawancara dengan mahasiswa berkode AE yang memberikan jawaban tersebut.

P: "bagaimana strategi awalmu pada nomor 10 ?"

AE: "nilai mutlak itu menjadi positif dan negatif dulu dalam 2 kemungkinan.

P: $\quad$ "dari mana $\geq$ dan $\leq$ ini?"

AE: "kalo yang ini nilai mutlaknya positif, jadi tidak merubah tanda. kalo yang ini nilai mutlaknya negatif, jadi $\geq$ maka $\leq$.

P: "lanjutkan strategi dan langkah penyelesaianmu?"

AE: "dikalikan silang jadi $-6 \geq x-2$ "

P: “apakah penyebut $(x-2)$ tidak memiliki syarat?"

AE: "setau saya langsung dikalikan gini."

P: "bagaimana kemungkinan kedua?"

AE: "sama caranya dikalikan silang."

P: "apakah penyebut $(\mathrm{x}-2)$ nya sama tidak memiliki syarat?"

AE: "ya"

Dari cuplikan wawancara diperoleh penjelasan bahwa strategi yang digunakan mahasiswa berkode AE untuk menyelesaikan adalah menjadikan nilai mutlak bernilai positif dan negatif lalu dikalikan. Jika nilai mutlak bernilai positif maka tidak merubah tanda, serta ruas kiri dan kanan tetap. Jika nilai mutlak bernilai negatif maka $\geq$ menjadi $\leq$, serta ruas kiri tetap tapi ruas kanan berubah tanda yakni $\frac{1}{6}$ menjadi $-\frac{1}{6}$. Kemudian mengalikan silang pada ke-2 ruas.

Kesalahan mahasiswa berkode AE terjadi pada saat mengalikan silang yang tidak memperhitungkan syarat penyebutnya yakni $(x-2)$ khususnya pada kemungkinan 1 . Seharusnya jika pada ruas kanan bernilai positif, ruas kiri harus bernilai positif karena tanda pertidaksamaannya adalah $\geq$. Jadi $(x-2)$ harus berubah terlebih dahulu menjadi $-(x-2)$, kemudian harus diperhitungkan pula bahwa syarat $x \neq 2$ pada ke dua kemungkinan.

Berdasarkan data hasil pekerjaan dan hasil transkrip wawacara pada mahasiswa yang diperoleh, semua mahasiswa tidak memperhitungkan syarat nilai $x$ pada nilai mutlak sebagai solusinya. Ditemukan pula ada mahasiswa yang menyelesaikan soal nilai mutlak menganggap bahwa nilai mutlak selalu bernilai positif ataupun menganggap tidak ada nilai mutlak dalam persamaan dan pertidaksaannya. Hal ini sejalan dengan hasil penelitian yang dilakukan oleh Ciltas dan Tatar (2011) bahwa mahasiswa menyelesaikan soal seolah-olah tidak ada nilai mutlak dalam persamaan dan pertidaksamaan yang diberikan.

Selain itu ditemukan sebagian besar mahasiswa menentukan himpunan penyelesaian soalsoal nilai mutlak berbentuk $|f(x)|=|g(x)|$ dengan menggunakan strategi "dikuadaratkan ke-2 ruas" dan soal yang berbentuk $|f(x)|<a$ atau $|f(x)|<a$ dengan menggunakan strategi teorema secara langsung dengan alasan bahwa strategi tersebut lebih cepat untuk digunakan, dari wawancara hal itu disebabkan karena mahasiswa mempersiapkan diri untuk mengikuti seleksi masuk perguruan tinggi. Fakta dari hasil penelitian menunjukkan bahwa mahasiswa mengalami ketakpahaman konsep jarak dan definisi nilai mutlak sebagai dasar konsep nilai mutlak. Sehingga terkesan bahwa mahasiswa hanya menghafal langkah-langkah prosedural atau tidak paham strategi penyelesaiannya. Hal ini sama dengan temuan peneliti sebelumnya pada matakuliah konsep dasar matematika bahwa mahasiswa terbiasa menghafal rumus atau cara cepat di jenjang sebelumnya (Amir, 2015).

Serta ditemukan juga bahwa mahasiswa mengalami kesulitan dalam memecahkan soal pertidaksamaan dalam bentuk nilai mutlak, sifat-sifat pertidaksamaan ataupun persamaannya. 
Vol. 2, No. 1, Oktober 2017, pp. 1-15

Temuan ini serupa dengan penelitian Priatna dan Sumartono (2009) mahasiswa PGSD mengalami kesulitan dalam menyelesaikan soal-soal persamaan dan pertidaksamaan.

Mahasiswa tidak dapat menjawab himpunan penyelesaian secara tepat. Mahasiswa mengalami miskonsepsi dalam memahami konsep interval pertidaksamaan pada bilangan real sehingga mereka salah dalam menuliskan himpunan penyelesaian sebagai solusi akhirnya. Sejalan dengan temuan tersebut, El-khateeb (2016) menemukan mahasiswa mengalami miskonsepsi dan ketakpahaman dalam memecahkan masalah pertidaksamaan.

Kesulitan mahasiswa ditemukan lebih bervariasi pada soal open ended, sehingga soal open ended dapat menjadi alternatif instrumen untuk mengevaluasi pendekatan suatu pembelajaran. Setiana (2016) menyatakan melalui metode open ended problem, siswa akan mendapat kesempatan untuk mengeksplorasi berbagai macam teknik penyelesaian.

Serta ditemukan pula ketakpahaman mahasiswa dalam penggunaan algoritma pembagian ataupun pemfaktoran dalam langkah proseduralnya dan ada mahasiswa yang tidak melakukan pengecekan kembali atas himpunan solusi yang didapat. Oleh karena masih banyak ditemukan kesulitan mahasiswa, maka mahasiswa harus mendapatkan kesempatan lebih banyak lagi dalam mengembangkan pengetahuannya untuk memecahkan masalah matematika (Widjajanti, 2009). Rosita (2014) juga menyebutkan dengan diberikan banyak latihan pemecahan masalah matematis, menyebabkan mahasiswa semakin memahami konsep dan berkembang pemikirannya.

\section{KESIMPULAN}

Berdasarkan analisis data dan pembahasan disimpulkan bahwa kesulitan yang dialami oleh mahasiswa adalah tidak dapat sepenuhnya mengaplikasikan konsep jarak dan definisi nilai mutlak sehingga langkah penyelesaian tidak tuntas; mengalami misunderstanding (ketakpahaman) pada konsep prasyarat (algoritma pembagian pemfaktoran, himpunan penyelesaian, dan interval peridaksamaan); mengalami misconceptions (kesalahpahaman) berupa anggapan nilai mutlak selalu bernilai positif; mengalami kesulitan dalam hal konseptual, prosedural, dan algoritma.

Faktor-faktor penyebab kesulitan diantaranya mahasiswa menghafal rumus dan teorema nilai mutlak tanpa memahami konsep dasar jarak dan definisi nilai mutlak, mahasiswa terbiasa menggunakan cara cepat untuk memecahkan masalah sebagai bekal untuk masuk perguruan tinggi.

Peneliti memberikan saran kepada para pendidik bahwa konsep dasar nilai mutlak harus lebih difokuskan pada konsep jarak dan definisi nilai mutlak sehingga siswa dapat memahami interpretasi geometrisnya. Kemudian pendidik bisa menerapkan strategi konsep penyelesaian menggunakan "dikuadratkan ke-2 ruas" ataupun lainnya yang lebih cepat untuk mendapatkan himpunan penyelesaian pada soal dalam bentuk tertentu secara lebih bermakna, sehingga mahasiswa terjadi pembiasaan pembelajaran agar mahasiswa tidak menggunakan rumus cepat dalam memecahkan masalah matematika. Konsekuensi positif yang didapat adalah mahasiswa tidak terjebak dalam langkah-langkah prosedural yang harus dihafal. Pembelajaran juga harus berorientasi konstuktivistik untuk menentukan dan menghilangkan kesulitan belajar mahasiswa dalam materi yang terkait dengan nilai mutlak agar tidak terjadi kesulitan dalam hal konseptual, prosedural, dan algoritma yang lebih kompleks dikemudian hari. 


\section{DAFTAR PUSTAKA}

Amir, M. F. (2015). Analisis Kesalahan Mahasiswa PGSD Universitas Muhammadiyah Sidoarjo Dalam Menyelesaikan Soal Pertidaksamaan Linier. Jurnal Edukasi, 1(2).

Ciltas Alper and tatar Enver. (2011). Diagnosing Learning Difficulties Related to the Equation and Inequality that Contain Terms with Absolute Value. International Online Journal of Educational Sciences, 3(2), 461-473.

El-khateeb, M. (2016). Errors Analysis of Solving Linear Inequalities among the Preparatory Year Students at King Saud University. Journal of Education and Practice, 7(12), 124-133.

Setiana, D. S. (2016). Comparison of CTL Learning Method And Open-Ended Method Application In Terms of Learning Styles Viewed From The Students' mathematics Learning Achievement And Interest. Jurnal Mercumatika: Jurnal Penelitian Matematika Dan Pendidikan Matematika, 1(1), 14-32. https://doi.org/10.26486/mercumatika.v1 i1.191

Usman, Hasbi. M., dan Bambang R.M.S. (2015). Pemahaman Mahasiswa Calon Guru Matematika Dalam Menyelesaikan Masalah Ketaksamaan Nilai Mutlak. Jurnal Peluang, 3(2).

Priatna, D., \& Sumartono, F. O. (2009). Analisis Kesulitan Mahasiswa Program D2 PGSD UPI Kampus Cibiru dalam Mata Kuliah Matematika. EDUHUMANIORA: Jurnal Pendidikan Dasar, 1(1).

Rosita, C. D. (2014). Kemampuan Penalaran Dan Komunikasi Matematis: Apa, Mengapa, Dan Bagaimana Ditingkatkan Pada Mahasiswa. Euclid, 1(1).

Widjajanti, D. B. (2009). Kemampuan pemecahan masalah matematis mahasiswa calon guru matematika: apa dan bagaimana mengembangkannya. In Seminar Nasional Matematika dan Pendidikan Matematika 2009. Jurusan Pendidikan Matematika FMIPA UNY. 